\title{
Regulation of the plasma non-esterified fatty acid concentration in the postprandial state
}

\author{
BY KEITH N. FRAYN, LUCINDA K. M. SUMMERS AND BARBARA A. FIELDING \\ Oxford Lipid Metabolism Group, Nuffield Department of Clinical Medicine, Radcliffe Infirmary, \\ Oxford $O X 26 H E$
}

\section{NON-ESTERIFIED FATTY ACIDS (NEFA): THEIR ROLE IN METABOLISM}

NEFA, also known as free fatty acids (FFA), are the form in which stored body fat is transported from adipose tissue to its sites of utilization (Fig. 1). Their importance was recognized in the 1950s once methods became available for their reliable measurement in plasma. Because of the rapid turnover of plasma NEFA, they constitute a large proportion of the 'energy flux' through the bloodstream, particularly in the post-absorptive and fasting states when their contribution relative to glucose increases. Thus, NEFA transport through the plasma is an essential part of normal life, and regulation of the plasma NEFA concentration is part of the normal pattern of metabolic regulation during feeding and fasting.

However, it has been appreciated since the work of Randle et al. (1963) that inappropriately elevated plasma NEFA concentrations could have adverse metabolic effects (Table 1). NEFA will compete with glucose for utilization by insulin-sensitive peripheral tissues (myocardium and skeletal muscle), leading to impaired glucose utilization. NEFA will stimulate hepatic glucose production, further impairing glucose tolerance. There is evidence from studies with isolated hepatocytes that NEFA may reduce hepatocyte insulin binding (Svedberg et al. 1990), thus reducing the normal large extraction of insulin which occurs on its first passage through the liver. The resulting systemic hyperinsulinaemia will lead ultimately to down-regulation of insulin-mediated processes, and hence insulin resistance. On the lipid side, the supply of NEFA to the liver is a major determinant of the rate of hepatic VLDL-triacylglycerol (TAG) secretion (Kissebah et al. 1976; Byrne et al. 1991). Increased NEFA supply, therefore, may lead to elevated VLDL-TAG secretion and hence hypertriacylglycerolaemia. There are wellestablished links between insulin resistance and other adverse conditions such as hypertension, and between insulin resistance, hypertriacylglycerolaemia and an atherogenic lipoprotein profile including a preponderance of small, dense LDL particles and a decreased HDL-cholesterol concentration (DeFronzo \& Ferrannini, 1991; Frayn, 1993). Therefore, inappropriately elevated NEFA concentrations may be seen as central to the insulin resistance syndrome (Frayn et al. 1996b). In addition, the well-recognized link between fat ingestion and activation of the coagulation cascade may reflect changes in plasma NEFA concentration (Mitropoulos et al. 1994; Silveira et al. 1994), although that area is outside the scope of the present review.

However, this is a simplistic black and white view of a substrate which is highly variable in concentration both from place-to-place within the circulation, and from minuteto-minute during the normal day (Fig. 2). The role of NEFA might be defined more clearly by asking: where and when are elevated NEFA concentrations 'inappropriate' or 'adverse'?

The answer to 'where?' is clear: many of the adverse effects discussed previously are mediated in the liver, and an increased supply of NEFA in the portal vein is likely to have 


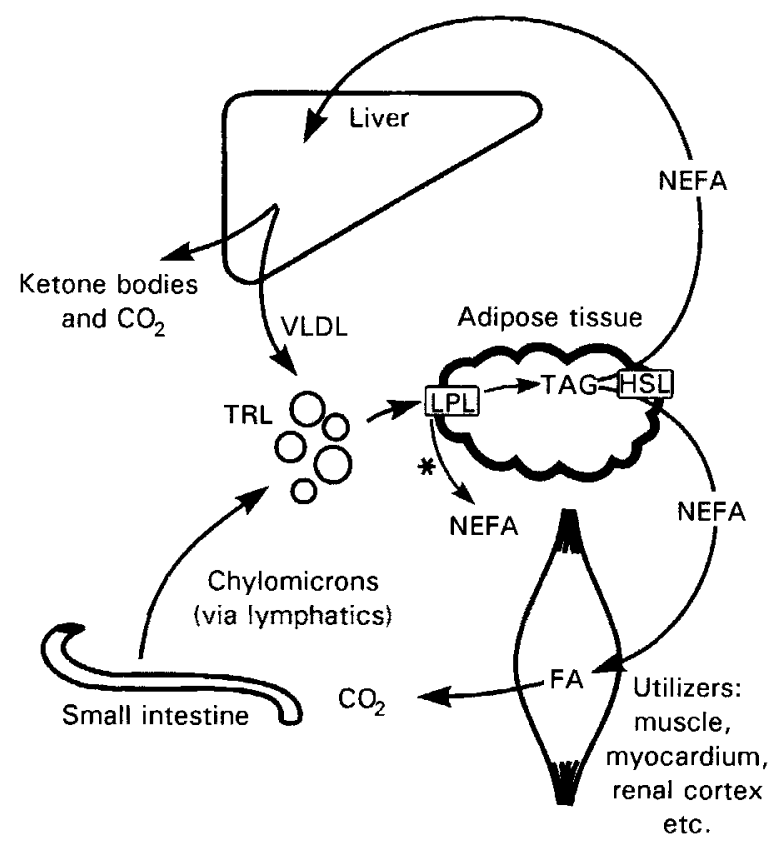

Fig. 1. Outline of non-esterified fatty acid (NEFA) metabolism. * This pathway for NEFA production (prominent in the postprandial period) is described in the text. FA, fatty acids; HSL, hormone-sensitive lipase (EC 3.1.1.3); LPL, lipoprotein lipase (EC 3.1.1.34); TRL, triacylglycerol-rich lipoproteins (chylomicrons and VLDL); TAG, triacylglycerol.

Table 1. Potential adverse consequences of inappropriately elevated plasma non-esterified fatty acid concentrations

\begin{tabular}{|c|c|}
\hline Primary consequence & Secondary effects \\
\hline Muscle glucose uptake & \multirow{3}{*}{ Glucose intolerance, insulin resistance } \\
\hline Hepatic insulin clearance & \\
\hline Hepatic glucose output & \\
\hline Hepatic VLDL secretion & \multirow{3}{*}{ Hypertriacylglycerolaemia } \\
\hline Lipoprotein lipase ( $E C$ 3.1.1.34) activity & \\
\hline Coagulation & \\
\hline
\end{tabular}

$\uparrow$, Increased; $\downarrow$, decreased.

particularly important consequences. This may explain the association between accumulation of intra-abdominal adipose tissue, liberating its NEFA into the portal vein, and cardiovascular risk factors. The association is probably strengthened by the fact that intra-abdominal adipose tissue seems to be more lipolytically active than subcutaneous adipose tissue (Arner et al. 1995).

The question 'when are elevated NEFA concentrations inappropriate?' is best answered by a consideration of the normal temporal pattern of NEFA concentrations (Fig. 2). Plasma NEFA concentrations in normal, healthy people are at their highest after an overnight fast or during aerobic exercise. In these situations the body needs to draw upon its stored fuel. Competition with glucose for peripheral utilization is appropriate; carbohydrate utilization is stimulated independently of insulin during exercise and even 


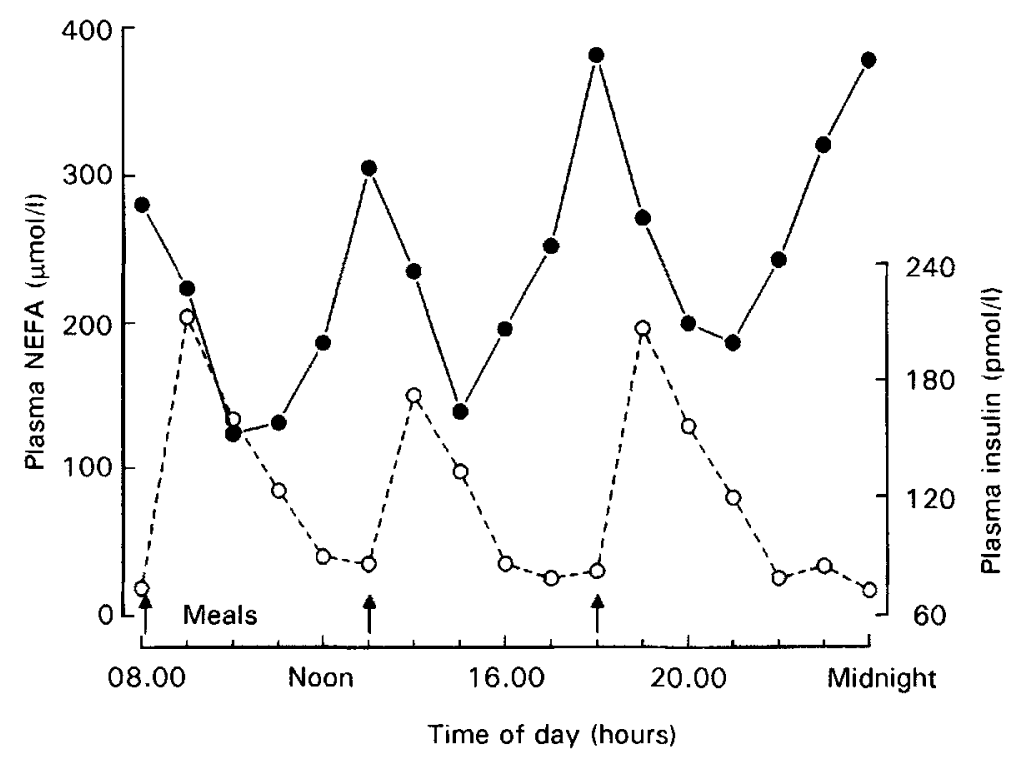

Fig. 2. Circadian variation of plasma non-esterified fatty acid (NEFA) concentrations (O) in normal, healthy subjects. Plasma insulin concentrations $\left(\mathrm{O}_{-}-\mathrm{O}\right)$ are also shown. As the plasma insulin concentration rises in response to a meal $(\uparrow)$, so the plasma NEFA concentration is suppressed. (Redrawn from Singer et al. 1985; with permission of the American Heart Association.)

seems to predominate over fatty acid utilization, whereas in fasting, sparing of carbohydrate in favour of fat utilization may be seen as an adaptive response. Plasma NEFA concentrations are, on the other hand, suppressed after a meal. This is entirely appropriate since in the postprandial period the body does not need to mobilize its fuel stores. Suppression of plasma NEFA concentrations allows unimpeded glucose utilization by peripheral tissues, removes an important stimulus for hepatic glucose production (therefore, allowing suppression by insulin), and likewise removes the major stimulus for hepatic VLDL-TAG secretion.

It is clear, therefore, that the adverse effects of elevated NEFA concentrations will be most apparent in the postprandial period. Failure to suppress plasma NEFA concentrations normally after a meal will result in impaired glucose utilization at a time when it should be stimulated to increase glucose clearance, will stimulate hepatic glucose production at a time when it should be suppressed, and will drive hepatic VLDL-TAG secretion so that VLDL will be competing with chylomicrons for peripheral clearance by lipoprotein lipase (EC 3.1.1.34; LPL).

This leads to the question: how is the plasma NEFA concentration regulated in the postprandial period compared with the post-absorptive state?

\section{REGULATION OF PLASMA NON-ESTERIFIED FATTY ACID CONCENTRATIONS IN THE POST- ABSORPTIVE AND POSTPRANDIAL STATES}

\section{Routes of non-esterified fatty acid delivery to the circulation}

Fasting plasma NEFA concentrations reflect primarily the rate of liberation of fatty acids from hydrolysis of adipose tissue TAG by the intracellular enzyme hormone-sensitive lipase (EC 3.1.1.3; HSL; Samra et al. 1996). HSL is regulated on a short-term basis by 
reversible phosphorylation and its molecular biology is well understood (Langin et al. 1996). Some of the fatty acids released by HSL may be re-esterified within adipose tissue and in principle this might be a point of control, but by $14 \mathrm{~h}$ of starvation NEFA : glycerol release from subcutaneous adipose tissue is very close to 3:1 (Samra et al. 1996), so this is not a major regulatory step in that situation. However, it may be, during shorter periods of fasting (e.g. during the night).

After ingestion of a meal, however, the activity of HSL is rapidly suppressed as the plasma insulin concentration rises. This suppression of HSL appears to be maintained as long as the plasma insulin concentration remains above $100-120 \mathrm{pmol} / 1$ (Frayn et al. 1995a). In practice this means that HSL is suppressed for a number of hours after a meal. In addition, the process of fatty acid esterification within adipose tissue is stimulated, leading to very efficient suppression of NEFA release from adipocytes (Coppack et al. 1990; Frayn et al. 1994). However, net release of NEFA from adipose tissue, although it may be completely suppressed shortly after a typical mixed meal, returns at a time when adipocyte fatty acid storage is also stimulated (Coppack et al. 1990; Frayn et al. 1994, 1995b). This bi-directional net movement of fatty acids is illustrated particularly clearly after a high-fat meal (Fig. 3). It is now clear that in this situation a large proportion of the NEFA released from adipose tissue arises not from the action of HSL on stored TAG, but from the intravascular action of LPL on plasma TAG.

The regulation of LPL has been reviewed extensively elsewhere (Bensadoun, 1991; Braun \& Severson, 1992; Olivecrona et al. 1993). In adipose tissue it is activated by insulin, leading to the storage of fatty acids in tissue in the postprandial period. However, whilst LPL is usually considered as an enzyme regulating fat storage, it may also play an important role in the delivery of NEFA into the circulation. It has long been recognized from animal experiments that about $50 \%$ of LPL-derived fatty acids are released directly into the plasma, as opposed to entrapment and esterification in tissues at the site of action (Bergman et al. 1971; Scow, 1977). This value is borne out in human studies of the tissue-

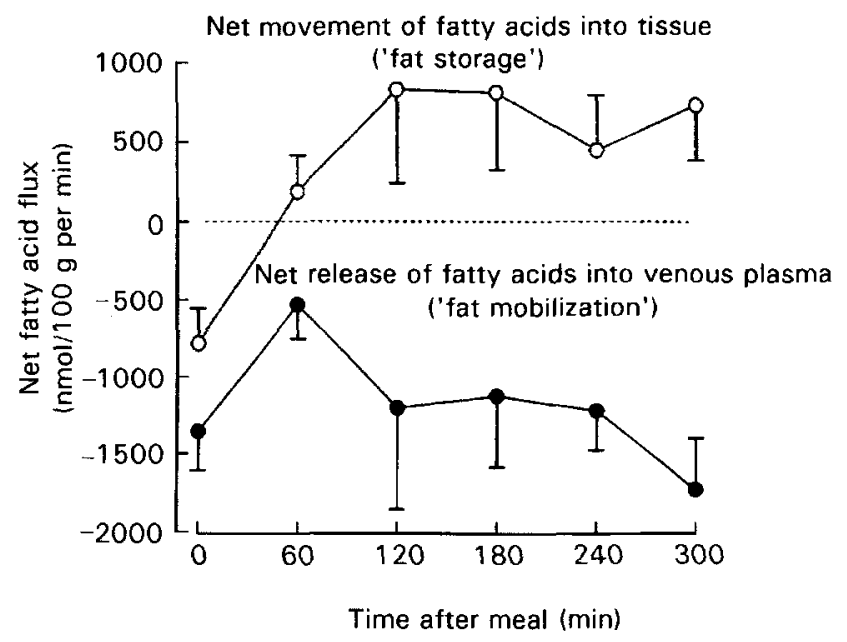

Fig. 3. Net fluxes of fatty acids in subcutaneous white adipose tissue in vivo in six normal subjects. A meal containing $80 \mathrm{~g}$ fat and $80 \mathrm{~g}$ carbohydrate (energy content $4.7 \mathrm{MJ}$ ) was given at time $0 .(\mathrm{O})$, Net flux of fatty acids from capillaries to cells; (O), net efflux of NEFA into the venous plasma (plotted as negative values). In the postprandial period there is bi-directional net movement of fatty acids, both into the cells and into the venous plasma. These fatty acids must arise from within the capillaries, i.e. from the action of lipoprotein lipase. The methods of calculation are given in Frayn et al. (1994). (Based on Fig. 4 of Frayn et al. 1995b.) 
specific release of fatty acids during the postprandial period (Frayn et al. 1994, 1995b). Interestingly, although skeletal muscle LPL also plays a role in removal of circulating TAG in the postprandial period, no such net 'overspill' of fatty acids is seen in that tissue; it appears to be a process specific to adipose tissue (Coppack et al. 1990). This might suggest that there is, in a teleological sense, some 'purpose' to this apparent inefficiency of LPL action in adipose tissue. We believe that the loss of a proportion of LPL-derived fatty acids into the plasma creates a metabolic branch point, thus conferring greater precision of regulation on the storage and mobilization of fatty acids in adipose tissue (Frayn et al. $1995 a$ ).

The role of LPL in delivery of NEFA during the postprandial period has been confirmed by a number of lines of evidence. If isotopically-labelled TAG-fatty acids are administered (either as part of a meal, or intravenously) then the label appears rapidly in the plasma NEFA pool, far too rapidly for fatty acids to have been taken up into tissues and then mobilized (Heimberg et al. 1974; Roust \& Jensen, 1993; Binnert et al. 1995; Fielding et al. 1997). The composition of the plasma NEFA pool (proportions of different fatty acids) changes after a meal, to reflect at least to some extent the composition of the dietary fat (Karpe et al. 1992; Griffiths et al. 1994; Fielding et al. 1996). In some situations there is a close correspondence between the plasma concentrations of chylomicron TAG after a meal, and plasma NEFA concentrations (Fielding et al. 1996). Our own measurements of arterio-venous differences across subcutaneous adipose tissue in normal healthy subjects suggest that the contribution of LPL-derived fatty acids to NEFA supply in the postprandial period is of major importance (Fig. 4).

It is clear, therefore, that during the postprandial period the rate of supply of NEFA to the circulation is governed not only by the activity of the intracellular enzyme HSL, but also, and perhaps to a major extent, by the release of LPL-derived fatty acids. Despite the potential importance of this route of NEFA delivery, however, very little is known of its

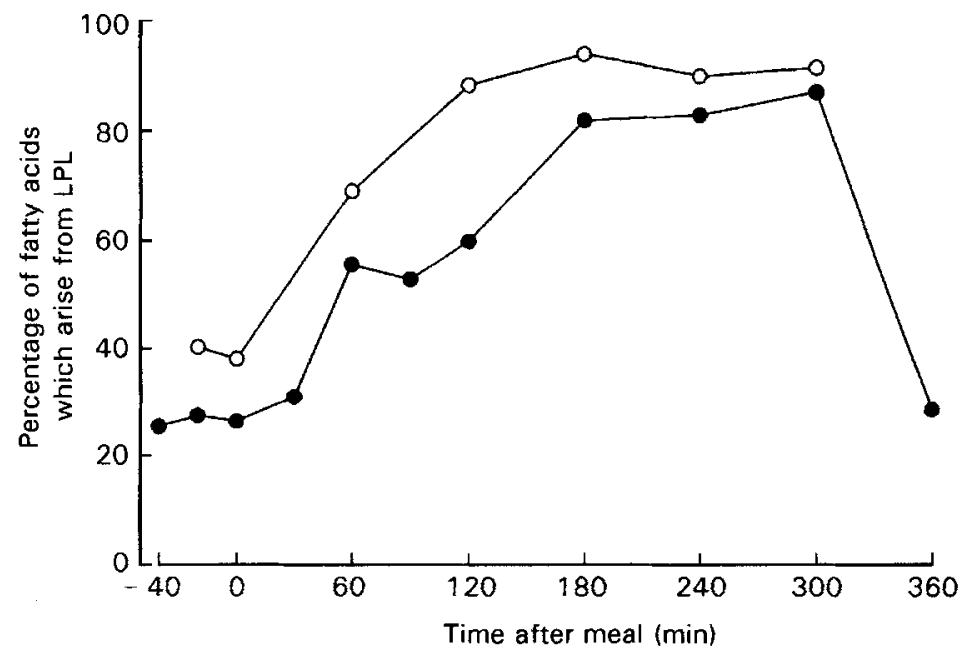

Fig. 4. Percentage of non-esterified fatty acids released from subcutaneous adipose tissue which may arise from the action of lipoprotein lipase (EC 3.1.1.34; LPL) on circulating triacylglycerols (TAG), rather than the intracellular action of hormone-sensitive lipase (EC 3.1.1.3) on stored TAG. (O), Mean values for thirteen normal subjects before and after eating a mixed meal (3.1 MJ, $33 \mathrm{~g}$ fat). (O), Median values for six normal subjects before and after eating a high-fat meal (for details, see Fig. 3). Calculations were described in Frayn et al. (1996a). (Data for the mixed meal were taken from Frayn et al. 1996a; reproduced with permission of Portland Press.) 
regulation. This contrasts sharply with the detailed knowledge of HSL regulation at a molecular level (Yeaman et al. 1994; Langin et al. 1996).

\section{Regulation of the delivery of lipoprotein lipase-derived fatty acids to the circulation}

Entrapment of fatty acids in adipose tissue in the postprandial period appears to reflect the coordinated regulation of a number of processes: activation of LPL, suppression of HSL and stimulation of the pathway of esterification. These operate together to generate a concentration gradient for NEFA from the site of LPL action to the cells, in contrast to the opposite situation during fasting. The release of LPL-derived fatty acids to the circulation, therefore, may reflect the balance between the rate of LPL action and the capacity for cellular uptake and esterification of fatty acids. Possible regulatory steps include the putative adipocyte fatty acid transporter (Abumrad et al. 1993), the capacity of intracellular fatty acid-binding proteins and the activity of the pathway of esterification. Little is known about the regulation of the first two steps. Fatty acid esterification in adipocytes has long been known to be stimulated by insulin (Leboeuf, 1965) and this has been confirmed in vivo (Coppack et al. 1989; Campbell et al. 1992; Frayn et al. 1994). Recently a novel and potent regulator of fatty acid esterification in adipocytes has been described, known as acylation-stimulating protein (ASP; Baldo et al. 1993). ASP is generated by the interaction of a series of three components of the alternate complement pathway, each secreted by adipocytes, and this pathway appears to be activated in the presence of chylomicrons (Cianflone et al. 1995). Thus, ASP would be produced and act locally at just the time when fatty acid entrapment in adipocytes would appear to be most 'beneficial' in avoiding the adverse effects of postprandial NEFA release outlined previously. The role of ASP in postprandial lipid metabolism is discussed in detail by Sniderman et al. (1997). Regulation of NEFA release in the postprandial period is summarized in Fig. 5.

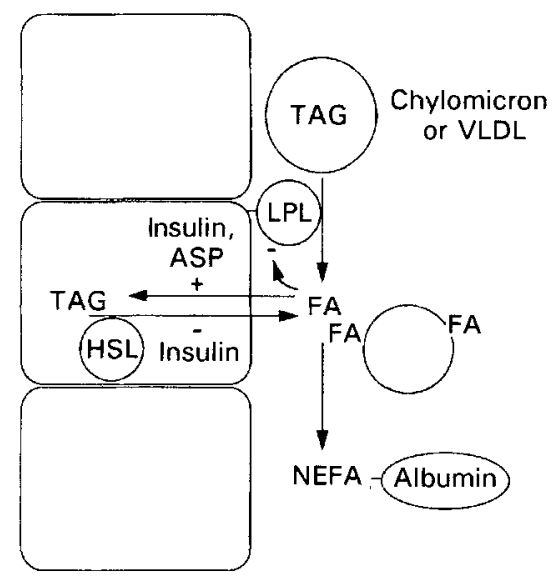

Fig. 5. Regulation of fatty acid release from adipose tissue in the postprandial period. Fatty acids (FA) are generated by the action of lipoprotein lipase (EC 3.1.1.34; LPL) on triacylglycerol (TAG)-rich lipoproteins, chylomicrons or VLDL. Cellular uptake of these fatty acids is stimulated by insulin and by acylation-stimulating protein (ASP). Concomitant fatty acid release by the action of hormone-sensitive lipase (EC 3.1.1.3; HSL) on intracellular TAG is normally suppressed by insulin. The extracellular fatty acids may have a negative feedback effect on LPL activity. Those FA not taken up into cells may remain transiently attached to lipoprotein remnants (a suggested activator of coagulation factor XII) but eventually become attached to plasma albumin and enter the plasma non-esterified fatty acid (NEFA) pool. (From Frayn et al. 1996b; reproduced with permission of Portland Press.) 


\section{ABNORMALITIES OF POSTPRANDIAL NON-ESTERIFIED FATTY ACID METABOLISM}

The previous discussion has been based on studies in normal healthy subjects. Are there reasons for supposing that dysregulation of NEFA delivery in the postprandial period exists? The answer is definitely positive, although so far as we are aware in none of these instances has a defect specifically in the LPL-pathway of NEFA delivery been shown.

Defects in insulin suppression of NEFA release have been shown in many conditions associated with insulin resistance and increased risk of CHD, including obesity (especially of the upper-body variety) (Jensen et al. 1989b), non-insulin dependent diabetes (Skowronski et al. 1991), and insulin-dependent diabetes (Singh et al. 1987; Jensen et al. 1989a). We have examined postprandial regulation of NEFA concentrations in severe obesity; failure to suppress NEFA concentrations normally is evident despite an exaggerated insulin response to a standard meal (Coppack et al. 1992; Summers et al. 1997). This defect reflects continued NEFA release from subcutaneous adipose tissue at a time when suppression of NEFA release is almost complete in lean controls (Coppack et al. 1992). A similar situation has been shown by tracer methodology in upper-body obese women (Roust \& Jensen, 1993). Such impairments of metabolic regulation may relate directly to features of the insulin resistance syndrome, prominent in these groups. Even amongst apparently healthy subjects, those showing least effective suppression of NEFA concentrations following an oral glucose load also show the greatest prevalence of features of the insulin resistance syndrome (Byrne et al. 1995). Familial combined hyperlipidaemia overlaps in many ways the insulin resistance syndrome, and it is of interest that increased NEFA concentrations following an oral fat load are a prominent feature of that condition (Castro Cabezas et al. 1993).

An interesting situation arises even in normal subjects when the protocol is varied from the single meal after an overnight fast which is the mainstay of so much research into postprandial metabolism. If normal subjects are given a second meal ('lunch') within a relatively typical time after a previous fatty meal ('breakfast'), unusual events follow. There is a rapid appearance of chylomicron TAG in the circulation, peaking at about $1 \mathrm{~h}$ following the lunch; this contrasts with the much slower appearance of chylomicron TAG following a single meal. These chylomicrons in fact carry TAG from the earlier meal (breakfast) which has presumably been stored somewhere in the meantime, and released rapidly in response to the arrival of a subsequent meal. However, unusually this peak of chylomicron TAG is accompanied by an elevation, or at least a maintenance, of the plasma NEFA concentration at a time when it would be suppressed after a single meal, and the composition of the plasma NEFA pool shows that NEFA arise in this situation from the chylomicron TAG pool (Fielding et al. 1996). We suggest that in this situation a rapid influx of chylomicron TAG is competently hydrolysed by LPL (perhaps still activated from the previous meal), but that the pathway of fatty acid uptake and esterification is, for some reason, unable to cope with this influx. Of course, we have described this as an unual situation, which it is in the context of metabolic experimentation, but in terms of daily life it may be a common one for many people. This may suggest one means by which regular intake of fatty meals is associated with adverse effects on cardiovascular risk.

\section{CONCLUSIONS}

We believe that there is considerable evidence that defects of NEFA metabolism in the postprandial period underlie common metabolic abnormalities, particularly those associated with the insulin resistance syndrome. We suggest that further research on the regulation of the plasma NEFA concentration in the postprandial period in conditions 
associated with the insulin resistance syndrome might be rewarding. Drugs reducing NEFA delivery by inhibition of HSL (nicotinic acid and derivatives) have shown some usefulness in treatment of hyperlipidaemia. We suggest that pharmacological agents increasing fatty acid entrapment in adipose tissue in the postprandial period might form a new generation of agents for treatment of the insulin resistance syndrome.

We thank other members of the Oxford Lipid Metabolism Group whose work has contributed to this review. We thank the Oxford Diabetes Trust, the British Heart Foundation and the Ministry of Agriculture, Fisheries and Food for direct support of some of the studies outlined here.

\section{REFERENCES}

Abumrad, N. A., el Maghrabi, M. R., Amri, E. Z., Lopez, E. \& Grimaldi, P. A. (1993). Cloning of a rat adipocyte membrane protein implicated in binding or transport of long-chain fatty acids that is induced during preadipocyte differentiation. Homology with human CD36. Journal of Biological Chemistry 268, 17665-17668.

Arner, P., Felländer, G., Reynisdottir, S., Lönnqvist, F. \& Livingston, J. N. (1995). Metabolic action and receptor signalling of insulin in human fat cells from different regions. Diabetologia 38, Suppl. 1, A141.

Baldo, A., Sniderman, A. D., St-Luce, S., Avramoglu, R. K., Maslowska, M., Hoang, B., Monge, J. C., Bell, A., Mulay, S. \& Cianflone, K. (1993). The adipsin-acylation stimulating protein system and regulation of intracellular triglyceride synthesis. Journal of Clinical Investigation 92, 1543-1547.

Bensadoun, A. (1991). Lipoprotein lipase. Annual Review of Nutrition 11, 217-237.

Bergman, E. N., Havel, R. J., Wolfe, B. M. \& Bohmer, T. (1971). Quantitative studies of the metabolism of chylomicron triglycerides and cholesterol by liver and extrahepatic tissues of sheep and dogs. Journal of Clinical Investigation 50, 1831-1839.

Binnert, C., Laville, M., Pachiaudi, C., Rigalleau, V. \& Beylot, M. (1995). Use of gas chromatography/isotope ratio-mass spectrometry to study triglyceride metabolism in humans. Lipids 30, 869-873.

Braun, J. E. A. \& Severson, D. L. (1992). Regulation of the synthesis, processing and translocation of lipoprotein lipase. Biochemical Journal 287, 337-347.

Byrne, C. D., Brindle, N. P. J., Wang, T. W. M. \& Hales, C. N. (1991). Interaction of non-esterified fatty acid and insulin in control of triacylglycerol secretion by Hep G2 cells. Biochemical Journal 280, 99-104.

Byrne, C. D., Wareham, N. J., Day, N. E., McLeish, R., Williams, D. R. R. \& Hales, C. N. (1995). Decreased nonesterified fatty acid suppression and features of the insulin resistance syndrome occur in a sub-group of individuals with normal glucose tolerance. Diabetologia 38, 1358-1366.

Campbell, P. J., Carlson, M. G., Hill, J. O. \& Nurjhan, N. (1992). Regulation of free fatty acid metabolism by insulin in humans: role of lipolysis and reesterification. American Joumal of Physiology 263, E1063-E1069.

Castro Cabezas, M., de Bruin, T. W. A., de Valk, H. W., Shoulders, C. C., Jansen, H. \& Erkelens, D. W. (1993). Impaired fatty acid metabolism in familial combined hyperlipidernia. A mechanism associating hepatic apolipoprotein B overproduction and insulin resistance. Journal of Clinical Investigation 92, 160-168.

Cianflone, K., Maslowska, M., Murray, I. \& Sniderman, A. D. (1995). The ASP pathway: evidence for a positive feedback loop. Triglyceride synthesis in human adipocytes. International Journal of Obesity 19, Suppl. 2, 69 Abstr.

Coppack, S. W., Evans, R. D., Fisher, R. M., Frayn, K. N., Gibbons, G. F., Humphreys, S. M., Kirk, M. J., Potts, J. L. \& Hockaday, T. D. R. (1992). Adipose tissue metabolism in obesity: lipase action in vivo before and after a mixed meal. Metabolism 41, 264-272.

Coppack, S. W., Fisher, R. M., Gibbons, G. F., Humphreys, S. M., McDonough, M. J., Potts, J. L. \& Frayn, K. N. (1990). Postprandial substrate deposition in human forearm and adipose tissues in vivo. Clinical Science 79, 339-348.

Coppack, S. W., Frayn, K. N., Humphreys, S. M., Dhar, H. \& Hockaday, T. D. R. (1989). Effects of insulin on human adipose tissue metabolism in vivo. Clinical Science 77, 663-670.

DeFronzo, R. A. \& Ferrannini, E. (1991). Insulin resistance. A multifaceted syndrome responsible for NIDDM, obesity, hypertension, dyslipemia, and atherosclerotic cardiovascular disease. Diabetes Care 14, 173-194.

Fielding, B. A., Callow, J., Owen, R. M., Samra, J. S., Matthews, D. R. \& Frayn, K. N. (1996). Postprandial lipemia: the origin of an early peak studied by specific dietary fatty acid intake during sequential meals. American Journal of Clinical Nutrition 63, 36-41.

Fielding, B. A., Frayn, K. N., Halliday, D., Bannister, P. A., Callow, J. \& Venkatesan, S. (1997). Rapid entry of dietary fatty acids into the plasma non-esterified fatty acid pool. Proceedings of the Nutrition Society 56, 162A.

Frayn, K. N. (1993). Insulin resistance and lipid metabolism. Current Opinion in Lipidology 4, 197-204.

Frayn, K. N., Coppack, S. W., Fielding, B. A. \& Humphreys, S. M. (1995a). Coordinated regulation of hormonesensitive lipase and lipoprotein lipase in human adipose tissue in vivo: implications for the control of fat storage and fat mobilization. Advances in Enzyme Regulation 35, 163-178. 
Frayn, K. N., Fielding, B. A., Humphreys, S. M. \& Coppack, S. W. (1996a). Nutritional influences on human adipose-tissue metabolism. Biochemical Society Transactions 24, 422-426.

Frayn, K. N., Humphreys, S. M. \& Coppack, S. W. (1995b). Fuel selection in white adipose tissue. Proceedings of the Nutrition Society 54, 177-189.

Frayn, K. N., Shadid, S., Hamlani, R., Humphreys, S. M., Clark, M. L., Fielding, B. A., Boland, O. \& Coppack, S. W. (1994). Regulation of fatty acid movement in human adipose tissue in the postabsorptive-to-postprandial transition. American Journal of Physiology 266, E308-E317.

Frayn, K. N., Williams, C. M. \& Arner, P. (1996b). Are increased plasma non-esterified fatty acid concentrations a risk marker for coronary heart disease and other chronic diseases? Clinical Science 90, 243-253.

Griffiths, A. J., Humphreys, S. M., Clark, M. L., Fielding, B. A. \& Frayn, K. N. (1994). Immediate metabolic availability of dietary fat in combination with carbohydrate. American Journal of Clinical Nutrition 59, 53-59.

Heimberg, M., Dunn, G. D. \& Wilcox, H. G. (1974). The derivation of plasma-free fatty acids from dietary neutral fat in man. Journal of Laboratory and Clinical Medicine 83, 393-402.

Jensen, M. D., Caruso, M., Heiling, V. \& Miles, J. M. (1989a). Insulin regulation of lipolysis in nondiabetic and IDDM subjects. Diabetes 38, 1595-1601.

Jensen, M. D., Haymond, M. W., Rizza, R. A., Cryer, P. E. \& Miles, J. M. (1989b). Influence of body fat distribution on free fatty acid metabolism in obesity. Journal of Clinical Investigation 83, 1168-1173.

Karpe, F., Olivecrona, T., Walldius, G. \& Hamsten, A. (1992). Lipoprotein lipase in plasma after an oral fat load: relation to free fatty acids. Journal of Lipid Research 33, 975-984.

Kissebah, A. H., Alfarsi, S., Adams, P. W., Seed, M., Folkard, J. \& Wynn, V. (1976). Transport kinetics of plasma free fatty acid, very low density lipoprotein triglycerides and apoprotein in patients with endogenous hypertriglyceridaemia. Effects of 2,2-dimethyl,5(2,5-xylyloxy) valeric acid therapy. Atherosclerosis 24, 199 218.

Langin, D., Holm, C. \& Lafontan, M. (1996). Adipocyte hormone-sensitive lipase: a major regulator of lipid metabolism. Proceedings of the Nutrition Society 55, 93-109.

Leboeuf, B. (1965). Regulation of fatty acid esterification in adipose tissue incubated in vitro. In Handbook of Physiology Section 5: Adipose Tissue, pp. 385-391 [A. E. Renold and G. F. Cahill, editors]. Washington, DC: American Physiological Society.

Mitropoulos, K. A., Miller, G. J., Martin, J. C., Reeves, B. E. A. \& Cooper, J. (1994). Dietary fat induces changes in factor VII coagulant activity through effects on plasma free stearic acid concentration. Arteriosclerosis \& Thrombosis 14, 214-222.

Olivecrona, T., Liu, G., Hultin, M. \& Bengtsson-Olivecrona, G. (1993). Regulation of lipoprotein lipase. Biochemical Society Transactions 21, 509-513.

Randle, P. J., Garland, P. B., Hales, C. N. \& Newsholme, E. A. (1963). The glucose fatty-acid cycle. Its role in insulin sensitivity and the metabolic disturbances of diabetes mellitus. Lancet $\mathbf{i}, 785-789$.

Roust, L. R. \& Jensen, M. D. (1993). Postprandial free fatty acid kinetics are abnormal in upper body obesity. Diabetes 42, 1567-1573.

Samra, J. S., Clark, M. L., Humphreys, S. M., Macdonald, I. A. \& Frayn, K. N. (1996). Regulation of lipid metabolism in adipose tissue during early starvation. American Journal of Physiology 271, E541-E546.

Scow, R. O. (1997). Metabolism of chylomicrons in perfused adipose and mammary tissue of the rat. Federation Proceedings 36, 182-185.

Silveira, A., Karpe, F., Blombäck, M., Steiner, G., Walldius, G. \& Hamsten, A. (1994). Activation of coagulation factor VII during alimentary lipemia. Arteriosclerosis \& Thrombosis 14, 60-69.

Singer, P., Gödicke, W., Voigt, S., Hajdu, I. \& Weiss, M. (1985). Postprandial hyperinsulinemia in patients with mild hypertension. Hypertension 7, 182-186.

Singh, B. M., Palma, M. A. \& Nattrass, M. (1987). Multiple aspects of insulin resistance. Comparison of glucose and intermediary metabolite responses to incremental insulin infusion in IDDM subjects of short and long duration. Diabetes 36, 740-748.

Skowronski, R., Hollenbeck, C. B., Varasteh, B. B., Chen, Y.-D. I. \& Reaven, G. M. (1991). Regulation of nonesterified fatty acid and glycerol concentration by insulin in normal individuals and patients with type 2 diabetes. Diabetic Medicine 8, 330-333.

Sniderman, A., Cianflone, K., Summers, L., Fielding, B. \& Frayn, K. (1997). The acylation-stimulating protein pathway and regulation of postprandial metabolism. Proceedings of the Nutrition Society 56, 703-712.

Summers, L. K. M., Fielding, B. A., Ilic, V. \& Frayn, K. N. (1997). The effect of body mass index on postprandial non-esterified fatty acid suppression. Proceedings of the Nutrition Society 56, $95 \mathrm{~A}$.

Svedberg, J., Björntorp, P., Smith, U. \& Lönnroth, P. (1990). Free-fatty acid inhibition of insulin binding, degradation, and action in isolated rat hepatocytes. Diabetes 39, 570-574.

Yeaman, S. J., Smith, G. M., Jepson, C. A., Wood, S. L. \& Emmison, N. (1994). The multifunctional role of hormone-sensitive lipase in lipid metabolism. Advances in Enzyme Regulation 34, 355-370. 